\title{
Participação dos movimentos sociais na saúde de gays e lésbicas
}

\author{
Participation of social movements in gay and lesbian health
}

Romeu Gomes (https://orcid.org/0000-0003-3100-8091) ${ }^{1}$

${ }^{1}$ Departamento de Ensino, Instituto Fernandes Figueiras, Fundação Oswaldo Cruz. Av. Rui Barbosa $7164^{\circ}$ andar, Flamengo. 22250-020 Rio de Janeiro RJ Brasil. romeugo@gmail.com

\begin{abstract}
Since the beginning of the 20th centu$r y$, social movements have developed isolated or aligned actions to promote the right of gays and lesbians to health. This article explores the participation of social movements in gay and lesbian health from the framing perspective on social movements. A literature search was performed and a frame analysis was conducted of the discussions found in the selected articles. This article therefore constitutes a bibliographic essay. With respect to outcomes, the literature reveals alignment between social rights and Aids activism, resonating in improved access to healthcare for gays and lesbians. We conclude that, although the participation of social movements in the struggle for the right of gays and lesbians to health started at the beginning of the last century, it cannot be said, now at the end of the second decade of the 21st century, that the outcomes were entirely solid. In short, we highlight that: (1) in some societies, the claims of social movements have been transformed into political agendas, while in others precarious concessions have been made in relation to gay and lesbian rights; and (2) non-acceptance of the right of gays and lesbians to sexuality still exists.
\end{abstract}

Key words Social movements, Activism, Health, Gays and lesbians
Resumo Desde o início do século XX, os movimentos sociais desenvolvem ações isoladas ou alinhadas para promover o direito de gays e lésbicas à saúde. Este artigo explora a participação de movimentos sociais na saúde de gays e lésbicas a partir da perspectiva de enquadramento dos movimentos sociais. Foi realizada uma pesquisa bibliográfica, bem como uma análise de quadros das discussões encontradas nos artigos selecionados, logo constitui um ensaio bibliográfico. Com relação aos resultados, a literatura revela alinhamento entre direitos sociais e ativismo contra a Aids, com ressonâncias na melhoria do acesso à saúde de gays e lésbicas. Conclui-se que, embora a participação dos movimentos sociais na luta pelo direito de gays e lésbicas à saúde tenha começado no início do século passado, não se pode dizer, agora no final da segunda década do século XXI, que os resultados foram inteiramente sólidos. Em sintese, destaca-se que: (1) em algumas sociedades, as reivindicações dos movimentos sociais foram transformadas em agendas políticas, enquanto em outras foram feitas concessões precárias em relação aos direitos de gays e lésbicas; e (2) ainda não existe a aceitação do direito de gays e lésbicas à sexualidade.

Palavras-chave Movimentos sociais, Ativismo, saúde, Gays 


\section{Introdução}

Os movimentos sociais (MS) são entendidos como ações sociopoliticas construídas por atores coletivos de diferentes classes e estratos sociais (p.251) $)^{1}$. Ancorados, mas não limitados às associações, visam promover a mobilização em larga escala ${ }^{2}$. Assim, transferindo um problema do nível pessoal para o coletivo, o "associativismo" pode desempenhar um papel importante no desencadeamento de movimentos sociais ${ }^{2}$.

A concepção de Goffman sobre quadro ou moldura (frame) da experiência social serviu de fonte para vários estudos sobre MS. Para esse teórico, quadro se refere aos princípios de organização que governam os acontecimentos - pelo menos os sociais - e nosso envolvimento subjetivo neles...(p. 34) ${ }^{3}$. Berger ${ }^{4}$ observa que um quadro é uma metáfora para que aquilo que os sociólogos tentam expressar com palavras, tais como "pano de fundo", "contexto", ou por uma expressão "em termos de" (p.18). Por meio da análise de quadros, Goffman pode contribuir para se ampliar a inteligibilidade sobre os processos de interação, significação e ação por parte de atores individuais ou coletivos em contextos determinados (p. 146) A expressão inglesa frame é traduzida por autores brasileiros tanto como "quadro", tanto como "moldura".

Snow e Benford deram a principal contribuição em aplicar teoria goffmaniana na análise dos MS, uma vez que desviaram o foco da atenção dos frames de uma perspectiva exclusivamente cognitiva para uma perspectiva politico-cultural, de entendimento do processo de mobilização social (p.89) ${ }^{1}$.

Benford e Snow criaram o conceito de macromolduras interpretativas (master frames) ao analisar o fenômeno simbólico que permite que diversas organizações se articulem momentaneamente em torno de determinada interpretação compartilha$d a(\text { p. } 152)^{5}$.

Além desse conceito, vários aspectos teóricos permeiam os estudos de Benford e Snow. Para o propósito deste trabalho, destacam-se dois deles: alinhamento de enquadramento e ressonância. $O$ primeiro voltado para a compreensão dos processos de formação de molduras interpretativas da ação coletiva, enquanto o segundo se relaciona aos resultados do enquadramento interpretativo. Em relação ao primeiro conceito, Snow et al. ${ }^{6}$ o destacam como uma condição necessária para a participação das organizações de MS. Segundo esses autores, tal alinhamento consiste numa vinculação de orientações interpretativas para que interesses, valores e crenças individuais e ideologias dessas organizações sejam congruentes e complementares. Assim, o engajamento de potenciais aderentes e a manutenção de militantes por parte dos movimentos sociais ocorrem por meio da convergência entre as molduras interpretativas dos indivíduos e as desenvolvidas e veiculadas pelas organizações de movimentos sociais (p. 150) ${ }^{5}$. Quatro processos - relacionados, mas não idênticos - podem integrar o alinhamento: o estabelecimento de pontes entre molduras (conexão entre as interpretações do movimento e as interpretações socialmente estabelecidas semelhantes); amplificação de molduras (destaque de determinada categorização socialmente disponível que seja favorável ao movimento); extensão de molduras (extensão dos interesses dos movimentos sociais para incluir outras questões e preocupações importantes estabelecidas socialmente) e transformação de molduras (substituição de determinados significados sociais por novos entendimentos $)^{5}$. Em outro trabalho, Snow e Benford ${ }^{7}$ destacam que os MS utilizam quadros que atribuem significados a eventos e condições relevantes para que possam angariar apoio de espectadores e desmobilizar antagonistas.

Em relação ao conceito de ressonância, Benford e Snow ${ }^{8}$ o destacam como relevante para a eficácia ou potência de mobilização dos enquadramentos. Silva et al. ${ }^{5}$ observam que os resultados dos processos interpretativos relacionam-se diretamente a três fatores: 1) características dos criadores e porta-vozes do movimento (credibilidade, carisma, orientação estratégica e papel institucional); 2) semelhança entre enquadramento contestatório e cultura vigente (que pode gerar dilemas em ter uma maior aceitação com menor potencial contestatório ou agir voltado para a transformação que pode ser recebida com menos simpatia por parte dos interlocutores) e 3) balanço entre elementos ressonantes e elementos contestatórios (contextualização do enquadramento num campo de conflito para que sejam oferecidas respostas que neutralizem as interpretações rivais). Esse terceiro fator é uma alternativa de minimizar a necessidade de os MS terem características iguais à cultura vigente ${ }^{5}$.

Embora haja críticas às concepções teóricas de Benford e Snow - uma das quais é a ênfase na dimensão cognitiva para a interpretação da ação coletiva - Silva et al. ${ }^{5}$ destacam a importância desses autores, uma vez que pesquisaram as variáveis que afetam a aceitação de quadros de ação coletiva interpretativa pelo público-alvo das organizações, analisando a potência mobilizadora de uma variedade de quadros interpretativos (p. 151) . 
As ações dos MS podem contribuir para o desenvolvimento e a transformação da sociedade civil e politica (p. 251) ${ }^{1}$, em diversas áreas, sejam elas mais gerais, como a dos direitos civis, sejam mais específicas, como a educação e a saúde.

Mais especificamente, movimentos sociais ligados a direitos sociais, Aids, feminismo etc. deram uma contribuição significativa ao movimento homossexual $(\mathrm{MH})$. Esse movimento - que surgiu em alguns países no final da década de 1960 - tem quatro décadas de existência no Brasil ${ }^{9}$. Nos EUA é considerado inovador e o movimento brasileiro surgiu praticamente pegando carona em precedentes internacionais (p. 49) ${ }^{10}$. Grandes avanços foram feitos durante esse período e enormes desafios foram enfrentados em um cenário de contratempos e ofensivas contra os direitos de gays, lésbicas, bissexuais, travestis e transexuais. Segundo Trevisan ${ }^{10}$, quando o governo brasileiro começou a financiar programas sobre direitos dos homossexuais e Aids, o discurso de ativistas gays foi confundido com o discurso oficial do governo. No entanto, o movimento homossexual brasileiro expandiu-se, incluindo uma série de diferentes sujeitos políticos e ficou conhecido como o movimento LGBT (lésbicas, bissexuais, travestis e transexuais). No final dos anos de 1990, o movimento articulou um amplo conjunto de arranjos no que diz respeito à organização e à dinâmica interna e sua relação com outros atores sociais ${ }^{11}$. Em 2008, já era evidente que a participação da comunidade LGBT poderia ajudar os homossexuais a transformar a arte de aceitar diferenças em um objetivo político (p. 59) ${ }^{10}$. No entanto, agora, no final da década de 2010, ainda há muito a ser construído e discutido no que diz respeito aos direitos sociais e de saúde dos homossexuais.

Diante da relativamente longa história do movimento homossexual, vale a pena refletir sobre a participação dos movimentos sociais até hoje em questões ligadas à saúde de gays e lésbicas.

Com base nessas considerações iniciais, este artigo examina a participação de movimentos sociais na saúde de gays e lésbicas na perspectiva do enquadramento. Esta análise se concentra em grupos e associações ancorados nas interrelações diretamente estabelecidas entre seus membros. Entende-se que isso não se desvia da dimensão do movimento social, uma vez que esses movimentos inspiram ou servem como ponto de referência para esses grupos.

\section{Metodologia}

Este estudo é parte de uma pesquisa mais ampla que tem como objeto agendas de saúde de grupos de gays e lésbicas. Pesquisa apoiada pelo CNPq e aprovada pelo Comitê de Ética do Instituto Nacional de Saúde da Mulher, da Criança e do Adolescente Fernandes Figueira/Fundação Oswaldo Cruz (IFF/Fiocruz).

O trabalho se caracteriza, inicialmente, como um estudo bibliográfico de abordagem qualitati$\mathrm{va}$, tendo como fonte o artigo científico. O estudo bibliográfico além de possibilitar o alcance de um amplo número de informações e dados dispersos em várias publicações, também auxilia na melhor definição do quadro conceitual que envolve o objeto $^{12}$.

No entanto, o estudo não se limitou à extração e síntese de artigos. As discussões encontradas nesses artigos foram analisadas sob uma perspectiva de enquadramento da participação dos movimentos sociais na saúde de gays e lésbicas. Este artigo, portanto, constitui um ensaio bibliográfico.

A busca dos artigos ocorreu na Scopus, um dos maiores banco de dados do mundo, por meio da Elsevier (https://www.elsevier.com). Neste banco, realizaram-se consultas combinadas por meio das seguintes palavras-chave e boleadores: (Title-AbsKey (group ${ }^{*}$ or communit $^{*}$ or organization ) and key ( homosexual ${ }^{\star}$ ) or key (gays) or key $\left(\right.$ lesbian $\left.^{\star}\right)$ and key (health ${ }^{\star}$ ) and Title-Abs-Key ( movement or activism ${ }^{\star}$ or activist ${ }^{\star}$ or mobilization). Com essa busca, foram encontrados resumos de 130 artigos. A partir de leitura dos resumos, foram selecionados 32 porque neles mencionava-se a participação de movimentos, associações ou grupos homossexuais, de gays ou de lésbicas. Dos 32, não se conseguiu o texto completo de dois. Após a leitura integral dos 30 artigos, dez foram excluídos por não abordarem especificamente a participação de movimentos sociais em ações de saúde direcionadas a gays e lésbicas, resultando em uma amostra final de 20 artigos.

O primeiro tratamento das fontes foi de natureza descritiva no sentido de caracterizar os trabalhos quanto ao ano de publicação, país/região, periódico em que foi publicado, atores focalizados pelos MS/associações, temática de saúdedoença e abordagem metodológica.

Em um segundo tratamento analítico, com ancoragem na base teórico-conceitual conforme já mencionada, foram formuladas as seguintes questões a fim de se problematizar a produção: 1) Como é enquadrada a participação dos mo- 
vimentos sociais na saúde de gays e lésbicas? 2) Quais são os processos e resultados dessa participação?

\section{Caracterização das fontes}

Dos 20 trabalhos selecionados na base escolhida (Quadro 1), mais de três quartos foram publicados nas duas primeiras décadas deste século, um quarto são da última década do século passado, em que o primeiro data de 1995 e o último de 2018. A América do Norte concentra mais da metade dos estudos e a outra parte abrange os que foram realizados em todos os outros continentes.

Observa-se que um quarto dos estudos foi publicado num nicho editorial que envolve periódicos voltados para a homossexualidade. E os demais se distribuem por várias áreas da saúde. A temática predominantemente no conjunto das fontes é o HIV/Aids, com dois quintos dos estudos. Entretanto não se deve desconsiderar que uma diversidade de outras discussões se afigura em torno de questões da homossexualidade, tais como mobilização política, envelhecimento saudável, direitos sexuais e câncer. Predominam as análises documentais e ensaios. Em outras palavras, as discussões ancoram-se principalmente em fontes secundárias. Nem todos os estudos explicitam seus métodos. Para fins classificatórios, aqueles que não fizeram isso e se constituíram em discussões livres sobre os temas foram considerados como ensaios.

Em alguns dos artigos, as discussões vão além do quadro de gays e lésbicas, englobando o contexto LGBT, particularmente nos publicados mais recentemente $\mathrm{e}^{13,21,22,27,31}$. Essas discussões não se aprofundam em questões relativas a todos os atores que compõem o contexto LGBT. Isso é de se esperar, dado que a pesquisa se concentrou na saúde de gays e lésbicas.

\section{Emolduramento da participação dos Movimentos Sociais na saúde de gays e lésbicas}

Pelo menos dois quadros principais se destacam na literatura selecionada: direitos sociais e ativismo contra a Aids. Estas estruturas mestras ajudam a entender a articulação entre diferentes movimentos sociais e organizações estatais e civis para defender as demandas, lutas e reivindicações dos movimentos homossexuais em relação à saúde de gays e lésbicas.

Os direitos sociais, segundo Nunes ${ }^{33}$, podem ser considerados como um exemplo de quadro mestre dentro dos protestos dos MS em geral. Os $\mathrm{MH}$, em específico, ancoraram suas reivindicações e lutas no quadro dos direitos ligados à sexualidade, cidadania e saúde.

Apesar de ter havido avanços internacionalmente no campo das políticas, esses direitos ainda não se tornaram realidade em várias nações e, em algumas sociedades, em que são legalmente aceitos, no cotidiano observam-se práticas homofóbicas. Essas práticas são melhores compreendidas no enquadramento cultural em que se inserem. Na República dos Camarões, por exemplo, as relações de homens do mesmo sexo estão associadas à psique coletiva como parte das práticas coloniais, representando símbolos do comportamento vergonhoso em que líderes coloniais forçavam líderes nacionais a fazer sexo para estabelecer quem era o chefe ${ }^{21}$.

$\mathrm{Na}$ comparação dos direitos sexuais entre gays e lésbicas, historicamente nem sempre os movimentos de lésbicas conseguiram conquistas similares às dos gays. Na Irlanda, em 1985, embora se reconhecesse que a comunidade lésbica fosse conhecida pelo seu ativismo, as análises acadêmicas, políticas e a mídia se concentraram mais em gays ${ }^{25}$. Apesar dessa consideração, na literatura consultada identificou-se uma extensa pesquisa voltada para aspectos demográficos, saúde mental e vida comunitária de 1925 lésbicas dos 50 estados dos EUA e vários territórios, realizada em $1984^{29}$. O estudo deu aos movimentos lésbicos acesso a uma estrutura que englobava os conceitos de saúde das lésbicas, como elas interagiam com a sociedade dominante e a conexão e apoio social na comunidade lésbica ${ }^{29}$. Nem sempre suas reivindicações conseguiram ressoar em garantia de direitos. Nos primeiros rascunhos dos relatórios relacionados à Quarta Conferência Mundial sobre Mulheres (Pequim, 1995), havia defesa e aceitação de opções lésbicas, mas - embora houvesse uma petição assinada por milhares de pessoas de 60 países - a delegação norte-americana foi intimidada pela política religiosa para silenciar esse tipo de afirmação ${ }^{31}$.

Por outro lado, em algumas situações, no interior dos MH ou na relação com outros MS, há casos em que lésbicas se sentem duplamente excluídas: em movimentos em que há homens gays sexistas e em movimentos feministas em que há mulheres homofóbicas ${ }^{23}$. Além da exclusão, elas podem se sentir estranhas, no movimento gay por serem mulheres e no movimento de mulheres por conta de sua homossexualidade e terem que desenvolver resistências frente à insistência de ter que escolher entre sua sexualidade e seu gênero ${ }^{30}$. 
Quadro I. Caracterização das fontes analisadas.

\begin{tabular}{|c|c|c|c|c|c|c|}
\hline Autores & Ano & Periódico & $\begin{array}{l}\text { País dos } \\
\text { autores }\end{array}$ & \begin{tabular}{|c|} 
Atores \\
focalizados pelos \\
Movimentos ou \\
Associações \\
\end{tabular} & Temática & Método \\
\hline $\operatorname{Adam}^{13}$ & 2011 & \begin{tabular}{|l} 
Journal of the \\
International AIDS \\
Society
\end{tabular} & Canadá & $\begin{array}{l}\text { Homossexuais } \\
\text { (no contexto } \\
\text { LGBT) }\end{array}$ & $\begin{array}{l}\text { Falhas epistêmicas na } \\
\text { prevenção do HIV }\end{array}$ & Revisão \\
\hline Berner $^{14}$ & 2011 & Sociology of Health & Suécia & Gays e lésbicas & Aids e doação de & Análise \\
\hline
\end{tabular}

\begin{tabular}{|c|c|c|c|c|c|c|}
\hline $\begin{array}{l}\text { Brown et } \\
\text { al. }{ }^{15}\end{array}$ & 2014 & $\begin{array}{l}\text { Health Promotion } \\
\text { Journal of Australia }\end{array}$ & Austrália & Gays e lésbicas & $\begin{array}{l}\text { Mobilização política } \\
\text { e HIV }\end{array}$ & Ensaio \\
\hline Buring $^{16}$ & 1996 & $\begin{array}{l}\text { Journal of } \\
\text { Homosexuality }\end{array}$ & EUA & Gays & Ativismo gay & $\begin{array}{l}\text { Análise } \\
\text { documental }\end{array}$ \\
\hline Epstein $^{17}$ & 1995 & $\begin{array}{l}\text { Science, Technology, \& } \\
\text { Human Values }\end{array}$ & EUA & Gays e lésbicas & Ativismo e Aids & Ensaio \\
\hline Frasca $^{18}$ & 2003 & $\begin{array}{l}\text { Reproductive Health } \\
\text { Matters }\end{array}$ & Chile & $\begin{array}{l}\text { Gays e } \\
\text { feminismo }\end{array}$ & Aids & Ensaio \\
\hline $\begin{array}{l}\text { Halkitis et } \\
\text { al. }{ }^{19}\end{array}$ & 2015 & $\begin{array}{l}\text { Journal of } \\
\text { Homosexuality }\end{array}$ & EUA & Gays & $\begin{array}{l}\text { Envelhecimento } \\
\text { saudável e gays }\end{array}$ & Ensaio \\
\hline $\begin{array}{l}\text { Johnson } \\
\text { et al. }{ }^{20}\end{array}$ & 2016 & Milbank Quarterly & EUA & Gays & $\begin{array}{l}\text { Aconselhamento/ } \\
\text { testagem e HIV }\end{array}$ & $\begin{array}{l}\text { Análise } \\
\text { documental } \\
\text { e de } \\
\text { entrevistas }\end{array}$ \\
\hline Kojoué $^{21}$ & 2017 & Critical African Studies & Camarões & $\begin{array}{l}\text { Homossexuais } \\
\text { (no contexto } \\
\text { LGBT) }\end{array}$ & $\begin{array}{l}\text { HIV/Aids e } \\
\text { redefinição da } \\
\text { cidadania }\end{array}$ & Ensaio \\
\hline $\begin{array}{l}\text { Landers et } \\
\text { al. }{ }^{22}\end{array}$ & 2011 & AIDS Behav & EUA & $\begin{array}{l}\text { Homossexuais } \\
\text { (no contexto } \\
\text { LGBT) }\end{array}$ & $\begin{array}{l}\text { Agenda de saúde } \\
\text { de homens gays e } \\
\text { bissexuais }\end{array}$ & Ensaio \\
\hline Laurie $^{23}$ & 2012 & $\begin{array}{l}\text { Journal of Lesbian } \\
\text { Studies }\end{array}$ & $\begin{array}{l}\text { Nova } \\
\text { Zelândia }\end{array}$ & Lésbicas & Estudos lésbicos & Ensaio \\
\hline $\begin{array}{l}\text { Logie \& } \\
\text { Lys }^{24}\end{array}$ & 2015 & $\begin{array}{l}\text { International Journal } \\
\text { of Circumpolar Health }\end{array}$ & Canadá & Gays e lésbicas & $\begin{array}{l}\text { Jovens indígenas e } \\
\text { LGBTQ }\end{array}$ & $\begin{array}{l}\text { Pesquisa } \\
\text { qualitativa }\end{array}$ \\
\hline Nolan $^{25}$ & 2018 & $\begin{array}{l}\text { The Journal of Policy } \\
\text { History }\end{array}$ & Irlanda & Gays e lésbicas & $\begin{array}{l}\text { Ativismo, Aids e } \\
\text { comunidade gay }\end{array}$ & Ensaio \\
\hline Parker $^{26}$ & 2009 & $\begin{array}{l}\text { J Acquir Immune Defic } \\
\text { Syndr. }\end{array}$ & EUA & Gays & $\begin{array}{l}\text { Sociedade civil e } \\
\text { HIV/Aids }\end{array}$ & Ensaio \\
\hline $\begin{array}{l}\text { Rama- } \\
\text { subban }^{27}\end{array}$ & 2008 & Global Public Health & Índia & $\begin{array}{l}\text { Lésbicas no } \\
\text { contexto LGBT }\end{array}$ & $\begin{array}{l}\text { Resistência à lei } \\
\text { contra a sodomia }\end{array}$ & Ensaio \\
\hline $\begin{array}{l}\text { Rosser et } \\
\text { al. }{ }^{28}\end{array}$ & 2008 & AIDS Care & EUA & Gays & $\begin{array}{l}\text { Mudanças estruturais } \\
\text { e comunidades gays }\end{array}$ & $\begin{array}{l}\text { Pesquisa } \\
\text { qualitativa }\end{array}$ \\
\hline $\begin{array}{l}\text { Ray \& } \\
\text { Bradford }^{29}\end{array}$ & 1999 & $\begin{array}{l}\text { Journal of the Gay } \\
\text { and Lesbian Medical } \\
\text { Association }\end{array}$ & EUA & Lésbicas & $\begin{array}{l}\text { Questões de saúde } \\
\text { lésbica }\end{array}$ & Inquérito \\
\hline Sullivan $^{30}$ & 2018 & $\begin{array}{l}\text { Journal of Lesbian } \\
\text { Studies }\end{array}$ & EUA & Gays e lésbicas & Câncer e lésbicas & Ensaio \\
\hline Tiefer $^{31}$ & 2002 & $\begin{array}{l}\text { Journal of Sex \& } \\
\text { Marital Therapy }\end{array}$ & EUA & $\begin{array}{l}\text { Gays e lésbicas no } \\
\text { contexto LGBT }\end{array}$ & Direitos sexuais & Ensaio \\
\hline Weigle $^{32}$ & 1995 & $\begin{array}{l}\text { Journal of the History } \\
\text { of Behavioral Science }\end{array}$ & $\begin{array}{l}\text { Grã- } \\
\text { Bretanha }\end{array}$ & Homossexuais & $\begin{array}{l}\text { Psicologia e } \\
\text { homossexualidade }\end{array}$ & $\begin{array}{l}\text { Análise } \\
\text { documenta }\end{array}$ \\
\hline
\end{tabular}

Fonte: Elaborado pelo autor.

Homens gays não-brancos também podem enfrentar mais a homofobia estrutural do que os brancos ${ }^{22}$. Ainda sobre as questões raciais, no conjunto das fontes analisadas, observa-se que comunidades homossexuais negras e brancas de Memphis não foram, de fato, capazes de resolver 
suas diferenças e trabalhar juntas para educar os memphianos sobre os perigos potenciais da Aids $^{16}$. Por conta de desigualdades raciais, nos EUA, em 2007, a Coalizão Nacional de Advocacia de Homens Gays Negros já era reconhecida como fundamental na defesa desses atores ${ }^{22}$. Questões de classes econômicas também influenciam a garantia de direitos de gays e lésbicas terem acesso a bens da saúde, uma vez que tais direitos, às vezes, dependem do capital financeiro desses atores ${ }^{30}$. Nesse sentido, a diversidade de fatores que influenciam o quadro dos direitos de gays e lésbicas requer que sejam exploradas intersecções de identidades, tais como as de sexualidade, etnia, gênero, ruralidade, urbanidade ${ }^{24}$ e classes socioeconômicas ${ }^{30}$.

Aparentemente na contramão de defesa dos direitos de gays, Berner ${ }^{14}$ apresenta o caso da Federação Sueca de Direitos de Gays e Lésbicas, criada em 1950, que, em 1983, quando só havia apenas dois casos de Aids no país, recomendou publicamente que homens homossexuais e bissexuais não doassem sangue. Segundo o autor, essa foi uma iniciativa única e primeira de uma organização gay em toda Europa. Frente a tal iniciativa, houve tensões internas e externas. Internas porque alguns membros achavam que essa recomendação poderia estigmatizar os gays e os bissexuais, fazendo com que esses atores fossem vistos como responsáveis pela Aids e não como vítimas. Externas porque as autoridades de saúde suecas avaliaram essa recomendação como histerismo. Mas a federação, em meio às incertezas acerca da Aids, tinha as informações privilegiadas sobre o risco de transfusão de sangue verificado na época nos EUA, obtidas por meio de uma ampla rede de movimentos. Para o autor, essa iniciativa foi uma das medidas mais importantes de prevenção de HIV no país. O caso em questão altera o enquadramento de direitos humanos plenos que rege a ação dos MS? Não. Houve uma ressignificação desse enquadramento. Reconsiderou-se o direito dos homossexuais em doar sangue, violando um ato altamente simbólico para o país porque entendeu-se que o sangue de certas pessoas poderia configurar risco mortal. Assim, para a federação em questão, o direito de receber sangue não contaminado era um direito igual para todos, enquanto o direito de doar sangue não era igual para todos ${ }^{14}$.

$\mathrm{O}$ ativismo internacional organizado em torno da Aids é outra macromoldura para a compreensão da participação dos MH na área da saúde. Nos EUA, o ativismo contra a Aids englobou grupos de lobby, prestadores de serviços e orga- nizações comunitárias com diversos interesses de pessoas de várias espécies, etnias, gêneros, preferências sexuais e "comportamentos de risco" de $\mathrm{HIV}^{17}$. Tal ativismo, nesse país, foi construído sobre a base do movimento gay e lésbico e emprestado de suas forças e inclinações particulares ${ }^{17}$.

Ainda que o ativismo da Aids tenha congregado diferentes MS e organizações, isso não significa que não tenha havido tensões, em determinado momento, entre as partes congregadas. Nos EUA, por exemplo, o estudo de Johnson et al. ${ }^{20}$ observa que em 1985, autoridades de saúde publica e ativistas concordaram que o aconselhamento para a infecção pelo HIV deveria ser implementado antes e depois do teste para que fosse assegurado que os pacientes fossem testados voluntariamente e compreendessem o significado de seus resultados. Mas, em 2014 as autoridades de saúde pública, em dúvidas se o aconselhamento funcionava e com a justificativa de custo, descontinuaram essa abordagem, que carregava importantes significados éticos e simbólicos para ativistas gays ${ }^{20}$.

Com o advento do tratamento da Aids, as comunidades gays desenvolveram formas distintas de envolvimento com a ciência para o conhecimento científico apropriado. $\mathrm{O}$ ativismo também permitiu uma mudança de foco ao longo do tempo do HIV/Aids para a saúde geral e o bem-estar de homens gays, incluindo homens mais velhos ${ }^{19}$.

Com o advento do tratamento da Aids, as comunidades gays desenvolveram formas distintas de envolvimento com a ciência para se apropriar do conhecimento científico. $\mathrm{O}$ ativismo em questão também possibilitou, ao longo do tempo, o deslocamento do HIV/Aids para uma perspectiva de saúde geral e bem-estar dos gays, envolvendo inclusive homens idosos ${ }^{19}$.

Nos anos 1980, a epidemia mortal de Aids foi respondida com uma organização feroz e ativismo comunitário liderado principalmente por homens gays. Entretanto, contemporaneamente, há um crescente reconhecimento de que a saúde de homens gays e bissexuais envolve muito mais do que a prevenção e o tratamento do HIV/ Aids, considerando-se disparidades significativas na saúde física, comportamental e mental, bem como o enfrentamento do estigma generalizado e a homofobia estrutural ${ }^{22}$.

Numa pesquisa ${ }^{28}$ realizada em 2007, com representantes de 17 cidades de 14 países (Estados Unidos, Canadá, Austrália, Nova Zelândia, África do Sul e mais nove países europeus), observouse que as comunidades gays estão passando por diferentes mudanças estruturais que podem ter 
implicações tanto nas discussões relacionadas à Aids, como no que se refere a direitos sociais em geral. Dentre os principais resultados de estudo destacam-se os seguintes: (a) nas cidades pesquisadas, a comunidade gay virtual era maior do que a comunidade física off-line; (b) na maioria das cidades, ainda que a população gay parecesse estável, houve um declínio da comunidade; (c) em algumas cidades havia maior integração de heterossexuais em bairros historicamente identificados por gays e menor participação em eventos gays e (d) menos voluntariado em organizações gays ou HIV/Aids. Os participantes se questionaram se com aceitação da sociedade, igualdade de direitos e tratamentos eficazes para o HIV, a comunidade gay existirá com tanta força no futuro. Frente a esse cenário, consideraram que o planejamento da prevenção do HIV, as intervenções, os serviços e as políticas deveriam ser revistos para abordarem os homens que fazem sexo com homens ${ }^{28}$.

As duas macromolduras aqui tratadas podem ser vistas como superpostas e também podem integrar outros quadros da experiência da participação de MS na saúde de gays e lésbicas. Um exemplo dessa superposição pode ser a criação da "Promoção da Saúde Sexual", incluindo um papel central para os direitos sexuais, em 2000, que teve a Organização Mundial da Saúde como coautora $^{31}$. Isso pode ter ocorrido, de um lado, por conta da defesa dos direitos das mulheres, dos gays e das lésbicas nos anos 1970 e, por outro lado, devido à pandemia da Aids nos anos $1980^{31}$.

A superposição dessas duas macromolduras podem também se afigurar como um conjunto de quadros. Parafraseando Berger, trata-se de quadros dentro de quadros dentro de quadros dentro de quadros (p. 18)

\section{Processos e resultados da participação dos Movimentos Sociais}

A literatura consultada aponta processos de MS integrando diferentes alinhamentos de quadros, principalmente tendo como foco o HIV/ Aids. Tal alinhamento envolve, principalmente, estratégias organizacionais para vincular interesses a provedores de recursos ${ }^{6}$. Nesse sentido, houve alinhamento tanto entre MS e organizações estatais, quanto entre diferentes MS.

No conjunto das fontes analisadas, destaca-se um caso que, já no início do século 20 , promoveu um alinhamento de diferentes quadros em prol da defesa da homossexualidade. Trata-se da Sociedade Sexológica Britânica (SSB), que operou de 1914 até o final dos anos 1930 em prol dos direitos homossexuais, incluindo personagens conhecidos da Psicologia (como Ernest Jones), Literatura (como Bernard Shaw), do campo da reforma sexual e social (como Stella Browne) e de médicos ${ }^{33}$. Por conta de pressões sociais, os membros da sociedade tiveram que adotar uma plataforma expandida que incluía todos os tipos de problemas e preocupações sexuais, tendo como "agenda oculta" os direitos dos homossexuais ${ }^{33}$.

No norte global, as comunidades homossexuais foram as primeiras a se mobilizarem frente à crise da Aids, impulsionando as agências estatais de saúde a superarem a inércia e até mesmo a antipatia ${ }^{13}$.

Ao Sul global, na década de 1980 no Brasil, em torno do movimento Aids, foram estabelecidas três importante parcerias: a Igreja Católica progressista; o movimento de Reforma Sanitária e o nascente movimento de Liberação gay ${ }^{26}$. Esse movimento, na década de 1990, conseguiu estabelecer pontes entre os movimentos feministas $\mathrm{e}$ saúde das mulheres, bem como com os usuários de programas de saúde com diabetes, dependência de drogas e condições de saúde mental ${ }^{26}$.

$\mathrm{Na}$ Austrália, o alinhamento estabelecido entre gays, usuários de drogas, profissionais do sexo, médicos, pessoas com Aids e governo possibilitaram a existência de ações voltadas para esse problema em múltiplos níveis sociais, estruturais, comportamentais e de serviços de saúde ${ }^{15}$.

O movimento contra a Aids dos EUA englobou uma ampla gama de ativistas de base, grupos de lobby, prestadores de serviços e organizações comunitárias; representa os diversos interesses de pessoas de várias espécies, etnias, gêneros, preferências sexuais e "comportamentos de risco" de HIV; e se envolveu em uma variedade de projetos dirigidos a várias instituições sociais ${ }^{17}$.

Nos EUA, muitas lésbicas e mulheres heterossexuais se engajaram no ativismo contra a Aids porque foram educadas no movimento feminista em saúde, na década de $1970^{17}$. Também nos EUA, no início do século, o processo de amplificação de quadros levou ao surgimento de uma nova onda de ativismo ancorada em uma política de identidade organizada por grupos específicos de doenças ${ }^{18}$. Outra ampliação do alinhamento se refere à estratégia do ativismo de lésbica em estabelecer conexão entre HIV/Aids e câncer de mama, nos anos 1990, em São Francisco (EUA) ${ }^{30}$. Ao implementar a estratégia de mudança de foco, um segmento desse grupo ativista chamou a atenção para o fato de que as preocupações lésbicas foram deixadas de fora do movimento de 
HIV/Aids e aumentou a conscientização sobre o maior risco de câncer de mama entre lésbicas. Como resultado, a doença tornou-se emblemática de necessidades mais amplas de saúde das lésbicas ${ }^{30}$.

$\mathrm{Na}$ Índia, ao se engajarem no ativismo da Aids, lésbicas urbanas e de classe média vislumbraram uma estratégica de crítica ao patriarcado e de luta pelos direitos sexuais dentro da estrutura maior dos direitos sexuais das mulheres ${ }^{27}$.

$\mathrm{O}$ alinhamento entre comunidades gays e lésbicas nem sempre foi efetivo. No Chile, por exemplo, a aliança entre gay-feminismo foi mais retórica do que real ${ }^{18}$. Já na Nova Zelândia, por se sentirem estranhas tanto por conta do sexismo de alguns membros conservadores de movimentos gays, quanto por causa da homofobia de algumas feministas heterossexuais, as lésbicas formaram grupos feministas lésbicos independentes ${ }^{23}$.

Outro tipo de alinhamento observado na literatura analisada foi o dos MS com o modelo biomédico. Nos EUA, o ativismo em relação à Aids conseguiu se alinhar ao modelo biomédico por meio de quatro táticas-chave: aquisição de competência cultural; representação política; junção de critérios epistemológicos e éticos, e tomada de posição em disputas metodológicas pré-existentes ${ }^{17}$. O tratamento da Aids sugere que os chamados "novos movimentos sociais" têm formas distintas de envolvimento com a ciência e esse os molda de maneiras bem distintas. Um extenso estudo da relação entre biomedicina e movimentos sociais poderia fornecer uma análise mais profunda e abrangente da construção do conhecimento médico e da transformação da prática médica ${ }^{17}$.

A participação dos ativistas em relação à Aids apontou o que alguns sociólogos afirmam, como Berg e Casper, de que a terapêutica médica não pode ser entendida separadamente das questões da construção do conhecimento e que a nossa concepção da prática científica pode ser promovida pela atenção cuidadosa aos detalhes locais do trabalho médico ${ }^{18}$.

Segundo Adam, alinhando-se às histórias de sucesso dos movimentos sociais, as ciências sociais podem promover uma agenda robusta que examina: formas sociais pelas quais as pessoas se organizam em rede; estratégias populares desenvolvidas frente ao risco do HIV; movimento sociohistórico de culturas sexuais e de drogas; dinâmica da mobilização popular para o avanço da saúde; fontes institucionais dos discursos sobre o HIV; e compreensão popular das tecnologias e mensagens do $\mathrm{HIV}^{13}$.
Em termos de políticas de saúde, a experiência da resposta ao HIV tem lições que são aplicáveis através da promoção da saúde, incluindo: a necessidade de aproveitar a mobilização e a ação da comunidade; sustentar a participação e a liderança em toda a parceria; comprometer-se com abordagens sociais, políticas e estruturais; $\mathrm{e}$ construir e usar evidências de várias fontes para se adaptar e evoluir continuamente ${ }^{15}$.

Com base na teoria dos quadros analíticos, observa-se que os alinhamentos em prol da saúde de gays e lésbicas, em específico, e dos direitos em geral, devem se complementar com constrangimentos ou incentivos das interações entre os ativistas e os detentores do poder, bem como do contexto histórico social e do regime político (p. 168) ${ }^{33}$.

Com base na literatura consultada, observase que as ações dos MS voltadas para a saúde de gays e lésbicas tiveram ressonâncias que podem ser consideradas como resultados positivos, ainda que sejam limitados por fatores de diversas ordens.

A ressonância do movimento de Aids dos EUA na década de 1970 permitiu que ele se tornasse o primeiro movimento social a converter "vítimas" de doenças em "especialistas ativistas", devido à sua potência mobilizadora, contribuindo significativamente para a prevenção de doenças ${ }^{13}$. Nas décadas seguintes, os movimentos garantiram que gays e lésbicas recebessem um status social único, indo contra a hegemonia de considerar a homossexualidade como doença ou imoralidade e reconstituindo-se como um "grupo de interesse" legítimo para liberar direitos civis $^{13}$. No interior desses movimentos havia médicos, cientistas, educadores, enfermeiras e outras variedades profissionais. Isso, de um lado, fez com que fosse estabelecida uma capacidade incomum de contestar os principais especialistas em seu próprio terreno e, por outro lado, facilitou o estabelecimento de pontes entre "especialistas" e "público"17.

Ainda nos EUA, por conta dos movimentos lésbicos, houve um ponto de partida no sentido de se obter recursos para inúmeros estudos de acompanhamento que buscam medir o risco de câncer de mama lésbica, uma área de pesquisa que continuava existindo em $2018^{30}$.

Na Irlanda, no fim dos anos 1970, a crise da Aids foi utilizada pela comunidade gay para criticar a criminalização de atos homossexuais, a ausência da educação sexual nas escolas, a limitação do acesso a preservativos e serviços de saúde sexual, fazendo com que o Estado se mostrasse pouco preparado frente aos desafios da Aidss ${ }^{25}$. 
$\mathrm{Na}$ Índia, A epidemia de HIV/Aids trouxe desafios para o Estado e para sociedade, impulsionando o questionamento, dentre outros aspectos, a heteronormatividade patriarcal e a participação de pessoas de sexualidades alternativas, que lançaram uma luta pela reforma da lei antisodo$\mathrm{mia}^{27}$. Anos após à Conferência Internacional do Cairo sobre População e Desenvolvimento, em 1994, as agências doadoras internacionais, ativas no campo da demografia e da saúde, e o efeito de demonstração do movimento pelos direitos dos homossexuais nos países ocidentais pressionaram a Îndia a incluir homens que fazem sexo com homens (HSH) em seus programas de controle de HIV/Aids, para defender os direitos desses atores e para abordar o seu papel de "população -ponte" em infectar mulheres ${ }^{27}$.

$\mathrm{Na}$ República dos Camarões, embora seja negada a cidadania plena aos homossexuais e haja pena de prisão para homossexuais, por conta da mobilização dos MS e de por conta de aportes de fundos internacionais, foram assegurados os direitos de grupos LGBT a terem acesso universal aos tratamentos antirretrovirais, criando-se, assim, uma "cidadania terapêutica" ${ }^{21}$. Questionase, no entanto, se, no contexto homofóbico, essa iniciativa é sustentável e até que ponto influencia o reconhecimento dos direitos civis das pessoas LGBT e $\mathrm{HSH}^{21}$.

Especificamente no Brasil, observa-se que a resposta ao HIV e à Aids, no final dos anos 1990, foi amplamente reconhecida como uma das mais eficazes do mundo ${ }^{26}$. O papel dos MS foi fundamental para se chegar a esse reconhecimento, que começou pela luta do acesso à assistência de boa qualidade para as pessoas com HIV/Aids e rumou para a reivindicação do direito ao tratamento ${ }^{26}$.

Com base em Benford e Snow ${ }^{8}$, é evidente que os enquadramentos das experiências dos movimentos sociais descritos na literatura tiveram ressonância, principalmente em relação à participação dos movimentos no acesso aos cuidados e tratamento de HIV/Aids. Esses resultados podem ser tributados tanto à potência mobilizadora quanto ao alinhamento dos movimentos com organizações governamentais e não-governamentais.

\section{Considerações Finais}

A luta pelo direito de gays e lésbicas à saúde e ao ativismo contra a Aids é mutuamente benéfica. Apesar de certas limitações, tal ativismo alcançou sucesso, seja na ancoragem de quadros na potência mobilizadora dos movimentos homossexuais, seja na transformação desses movimentos em partes integrais do ativismo. Em certas sociedades, esses movimentos ganharam exposição devido ao ativismo contra a Aids, reunindo ações e apoio financeiro de várias instituições nacionais e internacionais.

As conquistas de gays e lésbicas no campo da saúde foram alcançadas, em algumas regiões do planeta, devido às pontes que foram estabelecidas entre os movimentos desses atores com outros movimentos, a exemplo do feminismo. Junto a isso, em algumas sociedades, os movimentos gays e lésbicos foram se alinhando a quadros de reivindicações de outras identidades de gênero, como as de bissexuais e transgêneros, para conseguirem um maior potencial de mobilização em prol dos direitos sexuais não hegemônicos. Não se pode desconsiderar que nesse alinhamento entre organizações, em determinadas situações, a participação dos MS na saúde homossexual foi regulada ou deu lugar às ações governamentais por meio de programas específicos.

Ainda que a participação dos MS na luta pela saúde de gays e lésbicas tenha se iniciado nos primeiros anos do século passado, em pleno século XXI não se pode dizer que tenha havido resultados totalmente sólidos. Em alguns lugares, as reivindicações dos movimentos sociais foram transformadas em agendas políticas que abordam a saúde de gays e lésbicas, enquanto em outros foram feitas precárias concessões a esses atores ou ainda há muito a ser feito para garantir o direito à saúde das sexualidades não-hegemônicas. Apesar das leis que consagram esses direitos em alguns países, a manutenção do princípio de não discriminação continua sendo um grande desafio. Diante desse quadro multifacetado, não se pode ignorar a necessidade contínua de mobilização por movimentos sociais autônomos para garantir a proteção do direito à saúde para todas as identidades de gênero. 


\section{Referências}

1. Gohn MG. Teorias dos Movimentos Sociais: paradigmas clássicos e contemporâneos. São Paulo: Loyola; 1997.

2. Lüchmann LHH. Abordagens teóricas sobre o associativismo e seu efeito democráticos. Rev Bras Cien Sociais 2014; 29(85):159-179.

3. Goffman E. Os quadros da experiência social: uma perspectiva de análise. Petrópolis: Vozes; 2012.

4. Berger BM. Prefácio. In: Goffman E. Os quadros da experiência social: uma perspectiva de análise. Petrópolis: Vozes; 2012. p. 15-22.

5. Silva MK, Cotanda FC, Pereira MM. Interpretação e ação coletiva: o "enquadramento interpretativo" no estudo de movimentos sociais. Rev Sociol Polit 2017; 25(61):143-164.

6. Snow DA, Rochford Jr EB, Worden SK, Benford RD. Frame alignment processes, micromobilization, and movement participation. Am Sociol Rev 1986; 51(4):464-481.

7. Snow DA, Benford RD. Ideology, frame resonance and participant mobilization. Intern Social Mov Res 1988; 1:197-218.

8. Benford RD, Snow DA. Framing Processes and Social Movements: An Overview and Assessment. Annu Rev Sociol 2000; 26(1):611-639.

9. Green JN, Quinalha R, Caetano, Fernandes M. Apresentação. 40 anos do movimento LGBT brasileiro. In: Green JN, Quinalha R, Caetano, Fernandes M, organizadores. História do Movimento LGBT no Brasil. São Paulo: Alameda; 2018. p. 9-13.

10. Trevisan JS. Homocultura \& política homossexual no Brasil: do passado ao porvir. In: Costa $\mathrm{H}$, Bento B, Garcia W, Inácio E, Peres WS, organizadores. Retratos do Brasil homossexual: fronteiras, subjetividades e desejos. São Paulo: Editora da Universidade de São Paulo: Imprensa Oficial; 2010. p. 49-59.

11. Facchini R, Lins França I. De cores e matizes: sujeitos, conexões e desafios no Movimento LGBT brasileiro Sexualidad, Salud y Sociedad. Ver Latinoamericana 2009; 3:54-58

12. Lima TCS, Mioto RCT. Procedimentos metodológicos na construção do conhecimento científico: a pesquisa bibliográfica. Rev Katálysis [online]. 2007; 10:37-45. [acessado $2017 \mathrm{dez}$ 15]. Disponível em: http://www.scielo.br/scielo.php?script=sci_arttext\&pid=S1414-49802007000300004

13. Adam BD. Epistemic fault lines in biomedical and social approaches to HIV prevention. J Int AIDS Soc 2011; 14(Supl. 2):S2.

14. Berner B. The making of a risk object: AIDS, gay citizenship and the meaning of blood donation in Sweden in the early 1980s. Sociol Health Illn 2011; 33 (3):384-398

15. Brown G, O’Donnell D, Crooks L, Lake R. Mobilisation, politics, investment and constant adaptation: Lessons from the Australian health-promotion response to HIV. Health Promot J Austr 2014; 25(1):35-41.

16. Buring D. Gay activism behind the magnolia curtain: The Memphis Gay Coalition, 1979-1991. J Homosex 1996; 32(1):113-135.

17. Epstein S. The Construction of Lay Expertise: AIDS Activism and the Forging of Credibility in the Reform of Clinical Trials. Sci Techn Human Values 1995; 20(4), p. $408-437$.
18. Frasca T. Men and Women - Still Far Apart on HIV/ AIDS. Reprod Health Matters 2003; 11(22):12-20.

19. Halkitis PN, Kapadia F, Ompad DC, Perez-Figueroa R. Moving Toward a Holistic Conceptual Framework for Understanding Healthy Aging Among Gay Men. J Homosex 2015; 62 (5):571-587.

20. Johns DM, Bayer R, Fairchild AL. Evidence and the Politics of Deimplementation: The Rise and Decline of the "counseling and Testing" Paradigm for HIV Prevention at the US Centers for Disease Control and Prevention. Milbank Q 2016; 94(1):126-162.

21. Kojoué L. LGBT rights in a Republic of Therapy. HIV/ AIDS policies and the redefinition of citizenship in Cameroon. Crit Afr Stud 2017; 9(1):91-105.

22. Landers S, Pickett J, Rennie L, Wakefield S. Community perspectives on developing a sexual health agenda for gay and bisexual men. AIDS Behav 2011; 15(Supl. 1):S101-S106.

23. Laurie AJ. My New Zealand Lesbian Studies Through Time and Times. J Lesbian Studies 2012; 16(1):76-89.

24. Logie $\mathrm{CH}$, Lys $\mathrm{C}$. The process of developing a community-based research agenda with lesbian, gay, bisexual, transgender and queer youth in the Northwest Territories, Canada. (2015) Intern J Circumpolar Health 2015; 28188:1-2.

25. Nolan A. The gay community response to the emergence of AIDS in Ireland: Activism, covert policy, and the significance of an invisible minority. J Pol History 2018; 30(1):105-127.

26. Parker RG. Civil society, political mobilization, and the impact of Hiv scale-up on health systems in Brazil. J Acquir Immune Defic Syndr 2009; 52(Supl. 1): S49-S51.

27. Ramasubban R. Political intersections between HIV/ AIDS, sexuality and human rights: A history of resistance to the anti-sodomy law in India. Glob Public Health 2008; 3(Supl. 2):22-38.

28. Rosser BRS, West W, Weinmeyer R. Are gay communities dying or just in transition? Results from an international consultation examining possible structural change in gay communities. AIDS Care 2008; 20(5):588-595.

29. Ryan C, Bradford J. Conducting the National Lesbian Health Care Survey: First of its kind. J Gay Lesbian Med Assoc 1999; 3(3):91-97.

30. Sullivan M. A crisis emerges: Lesbian health between breast cancer and HIV/AIDS. J Lesbian Studies 2018; 22(2):220-234.

31. Tiefer L. The emerging global discourse of sexual rights. J Sex Marital Therapy 2002; 28(5);439-444.

32. Weigle DC. Psychology and homosexuality: The British Sexological Society. J Hist Behav Sci 1995; 31(2):137-148.

33. Nunes JH. Frame e identidade coletiva: uma perspectiva interacionista de análise de movimentos sociais. Contemporânea 2013; 3(1):143-172.

Artigo apresentado em 29/07/2019

Aprovado em 13/08/2019

Versão final apresentada em 15/08/2019

Editores-chefes: Maria Cecília de Souza Minayo, Antônio Augusto Moura da Silva 